\title{
Ultrastructural, histochemical and biochemical effects of titanium dioxide nanoparticles on adult male albino rat liver and possible prophylactic effects of milk thistle seeds
}

\author{
Original \\ Article \\ Eman E. Abu-Dief', Hekmat O. Abdel-Aziz', Eman K. Nor-Eldin ${ }^{1}$, Kamal M. \\ Khalil $^{2}$ and Eman E. Ragab ${ }^{1}$ \\ ${ }^{1}$ Department of Histology, Faculty of Medicine, ${ }^{2}$ Department of Chemistry, Faculty of \\ Science, Sohag University, Sohag, Egypt
}

\begin{abstract}
Introduction: Titanium dioxide nanoparticles (Tio2 NPs) are manufactured worldwide in large quantities for use in a wide range of applications. TiO2 NPs proved to damage liver function and induce an oxidative stress attack leading to liver toxicity. Milk thistle is an herbal supplement used to treat liver and biliary disorders. Silymarin, an active ingredient of milk thistle, is a strong antioxidant that promotes liver cell regeneration and stabilizes cell membranes.

Aim: To investigate the biochemical, the histological and the histochemical changes in the liver after administration of different doses of Tio2 NPs and to evaluate the possible protective role of Milk thistle against these effects.

Materials and Methods: Fifty adult male rats were divided into five groups; group I control, groups IIa and IIIa injected IP by $100 \mathrm{mg} / \mathrm{kg}$ and $150 \mathrm{mg} / \mathrm{kg} \mathrm{TiO} 2$ for 2 weeks, respectively and groups IIb and $111 \mathrm{~b}$ treated by oral milk thistle 4 weeks; one week prior, 2 weeks concomitant with IP $100 \mathrm{mg} / \mathrm{kg}$ and $150 \mathrm{mg} / \mathrm{kg} \mathrm{TiO} 2$, respectively and the forth week after injection. Thereafter, rats were sacrificed and liver as well as blood samples were collected for estimation of serum alanine aminotransferase (ALT) and alkaline phosphatase (ALPs). Liver samples were processed for examination by TEM and immunohistochemical staining with P53 and PCNA antibodies counted statistically positive cells.

Results: There was an increase in ALT and ALPs activities. Groups 11a and 111a treated by TiO2 showed signs of apoptosis and degeneration in the hepatocytes with nuclear changes and a significant increase in P53 and PCNA antibodies positive cells. These changes were ameliorated by concomitant injection with milk thistle with $\mathrm{TiO} 2$ in groups IIb and IIIb.

Conclusion: The alterations observed might be an indication of hepatocyte injury due to TiO2 NPs toxicity that interacts with proteins and enzymes in hepatic tissue leading to generation of reactive oxygen species induce hepatocytes apoptosis. Milk thistle, has a hepatoprotective effect probably by its antioxidant effect.
\end{abstract}

Received: 05 March 2017, Accepted: 12 February 2018

Key Words: Histochemical, liver, milk thistle, rats, TiO2 nanoparticles, ultrastructural.

Corresponding Author: Eman El Badry Ragab, Department of Histology, Faculty of Medicine, Sohag University, Sohag, Egypt, Tel.: 01004172416, E-mail: emanbadry_mb@yahoo.com

ISSN: 1110-0559, Vol. 41, No.1

\section{INTRODUCTION}

Nanotechnology has been used in the areas of health care, consumer products, clothes, electronics and sporting goods. The number of nanotechnology-based consumer products available on the world market exceeds 1000 . Nanomaterials have chemical, mechanical, optical, magnetic and biological properties that make them desirable for commercial and medical applications. Their toxicological impact is still under investigation and their effects on biological systems remain incomplete ${ }^{[1]}$.

Nanoparticles (NPs) are characterized by their small size and large surface area with an active group. These characters increase their chemical reactivity to enable them to penetrate into living cells. The impacts of NPs on human and the environment have been put forward by some scientists and organizations ${ }^{[2]}$. The toxic effects of NPs distributed mainly in important organ systems as lymph nodes, brain, lung, liver and kidney ${ }^{[3]}$. Titanium dioxide (TiO2) is among the manufactured NPs, is the earliest industrial product of nanomaterials in the world. $\mathrm{TiO} 2$ is a natural insoluble non silicate mineral oxide occurs in different forms and is widely used in the cosmetics, pharmaceutical and paint industries. $\mathrm{TiO} 2$ NPs can be absorbed into the body by inhalation, ingestion and dermal penetration due to their small size ${ }^{[4]}$. TiO2 NPs occur in different sizes, shapes, chemical compositions and four crystalline polymorphic forms. Rutile and anatase are the most common forms; some studies indicate that anatase $\mathrm{TiO} 2 \mathrm{NPs}$ is more cytotoxic than rutile $\mathrm{TiO} 2 \mathrm{NPS}^{[5]}$.

The liver is an active organ for detoxification and TiO2 NPs can penetrate liver cell. The toxic effect of $\mathrm{TiO} 2$ 
on the liver has been studied previously biochemically, physiologically and morphologically, however the effect of Tio2 NPs on the liver was found to be few in the literatures. $\mathrm{TiO} 2 \mathrm{NPs}$ proved to damage liver function and induce an oxidative stress attack leading to liver toxicity. TiO2 NPs reported to induce hepatocyte apoptosis and increase inflammatory reaction ${ }^{[4]}$. Li et al. ${ }^{[5]}$ stated that TiO2 NPs increase gene expression levels of reactive oxygen species (ROS) and cytochrome p450 (CYP1A). Bioactivation of CYP1A results in the formation of free radicals and ROS, which initiate lipid peroxidation and protein oxidation lead to damage hepatocellular membranes. This process is followed by the release of inflammatory mediators from activated hepatic macrophages lead to hepatic necrosis.

The use of herbal medicines from documented medicinal plants had a wide variety of clinical conditions including acute and chronic liver diseases. Silybum marianum (Milk thistle) is an effective therapeutic agent from natural products which may reduce the risk of hepatotoxins, besides, has a hepatoprotective effect ${ }^{[6]}$. It is used as herbal supplement treating liver and biliary disorders. It has been investigated for use as a cytoprotectant, an anti-carcinogen and a supportive treatment for liver damage from toxins. Silymarin is an active ingredient of Silybum marianum which has a strong antioxidant and anti-inflammatory properties that promotes liver cell regeneration and reduces blood cholesterol ${ }^{[7]}$. The protective antioxidant effects of Silybum marianum may be through impairing Tio2 NPs mediated oxidative stress. It decreases production of free radical derivatives, decreases CYP1A activity and increases in the hepatic glutathione level ${ }^{[8]}$.

\section{MATERIALS AND METHODS}

\section{I-Preparation of TiO2 nanoparticles}

In this method, the titanium (IV) tetraisopropoxide, Ti (OC3H7)4, (TTIP) used was 98\% pure liquid Aldrich (USA)). Isopropanol $(\mathrm{C} 3 \mathrm{H} 7 \mathrm{OH})$ was $99.9 \%$ pure liquid product of Aldrich. Preparation of nano-titania particles, $\mathrm{TiO} 2(\mathrm{~s})$, was carried out following the procedure described earlier by Khalil et al. 1998 ${ }^{[9]}$. X-ray diffraction (XRD) nitrogen adsorption/desorption isotherms and electron microscopy of Tio2 NPs were performed.

\section{II-Preparation of TiO2 solution}

Hydroxypropyl methylcellulose K4M 0.5\% (HPMC, $\mathrm{K} 4 \mathrm{M}$ ) was used as a suspending agent. $\mathrm{TiO} 2 \mathrm{NPs}$ powder was dispersed onto the surface of $0.5 \% \mathrm{w} / \mathrm{v}$ HPMC and then the suspending solutions were treated by ultrasonic for $30 \mathrm{~min}$ and mechanically vibrated for $5 \mathrm{~min}^{[10]}$.

\section{III-Preparation of Milk thistle suspension}

Milk thistle seeds were purchased from El Masria for Herbal Medicine in Sohag. They were grinded into powder
$15 \mathrm{~g}$ suspended in $100 \mathrm{~cm}$ boiled water for 15 minutes followed by filtration.

\section{IV-Animals and treatment}

A total number of 50 adult male Albino rats (150-200gm) were purchased from Assiut Experimental Animal Facility, Assiut University. Animals were housed in stainless steel cages in a ventilated animal room. All animals were given ad libitum access to Teklad rodent chow diet and water from sanitized bottle fitted with stropper and sipper tubes. They were acclimated to this environment for 5 days prior to the experiment. All procedures used in this experiment were approved with the local Ethics Committee. Animals were randomly divided into five groups, 10 animals each as the following: Group I: control group subdivided into three subgroups (3 rats each). Subgroup (i) kept without treatment, subgroup (ii) injected only by Hydroxypropyl methylcellulose and subgroup (iii) treated only by oral milk thistle. Group IIa: treated by intraperitonial injection (IP) of $\mathrm{TiO} 2(100 \mathrm{mg} / \mathrm{kg})$ daily for 2 weeks. Group IIb: treated by $15 \%$ oral milk thistle suspension twice daily for 4 weeks, one week prior and 2 weeks during $100 \mathrm{mg} / \mathrm{kg} \mathrm{TiO} 2$ treatment then one week after. Group IIIa: treated by IP TiO2 $(150 \mathrm{mg} / \mathrm{kg})$, daily for 2 weeks. Group IIIb: treated by $15 \%$ oral milk thistle suspension twice daily for 4 weeks; one week prior and 2 weeks during $150 \mathrm{mg} / \mathrm{kg}$ $\mathrm{TiO} 2$ treatment then one week after.

\section{$V$ - Liver function assessment}

Blood samples were collected and serum was harvested by centrifuging blood at $2500 \mathrm{rpm}$ for $10 \mathrm{~min}$. Liver function was evaluated with serum levels of ALPs and ALT. All biochemical assays were performed using a clinical automatic chemistry analyzer.

\section{VI- Liver samples}

The animals were sacrificed after being anaesthetized by ether. Liver samples of $0.1 \mathrm{ml}$ thick were taken from all animals for electron microscopy and immediately fixed in $2.5 \%$ glutaraldehyde for $24 \mathrm{~h}$ and embedded in Epon. Semithin sections (0.5-1um) were generated by using ultra microtome (LKB) then stained by:

A- Toludine blue: Ultrathin sections (500-800A) from selected areas of trimmed blocks were made and collected on copper grids. Ultrathin sections were contrasted with uranyl acetate for $10 \mathrm{~min}$ and lead citrate for $5 \mathrm{~min}$ and examined by the electron microscope.

B- Electron microscopy: Liver samples from all groups were immediately fixed in a $10 \%$ formalin solution and embedded in paraffin blocks, then sliced into $5 \mu \mathrm{m}$ in thickness mounted onto glass slides and stained with the following stains.

C- Immunohistochemistry using two antibodies: a- P53 Ab-8 (DO-7+Bp53-12) (tumor suppressor gene) b- PCNA Ab-1 (pc10) mouse MAb (proliferating cell 
nuclear antigen) bought from Thermo scientific company.

\section{VII-Morphometric studies}

The numbers of PCNA and P53 positive stained cells were counted in ten high power fields in each case using the light microscope Leica ICC50 Wetzlar (Germany) at the Histology Department, Faculty of Medicine, Sohag University.

\section{VIII-Statistical analysis}

Analysis of Variance (ANOVA) with a statistical significance of $P<0.05$ was used randomized designed according to other groups. Computations were performed with STATA version 9.2 software. All the analyses were performed in a blinded fashion.

\section{RESULTS}

\section{I- TiO2 NPs Characterization}

1- XRD Diffraction patterns: The hydrolysis products and its dry products at $120^{\circ} \mathrm{C}$, as shown in (Fig. 1), were non-crystalline to XRD [11].

2- Nitrogen adsorption isotherm: Nitrogen adsorption isotherm determined on the NanoT400 material and the BET plot is shown in (Figs. 2 and 3). The isotherm is of type IV of isotherms and exhibits a hysteresis loop of type $\mathrm{H} 2$, indicating mesoporous materials.

3- Transmission Electron Microscopy: Typical electron micrographs represent NanoT400 material is shown in (Fig. 4). The micrographs exhibit titania aggregates composed of very small poly-angular elementary particles of about $10 \mathrm{~nm}$ in diameter.

\section{II- Liver function enzymes: (Table 1, Figs. 5 and 6)}

There was very highly significant difference $(* * * *)$ between treated groups compared to the control group as regard levels of ALT and ALPs ( $p$ value $<0.0001)$.

\section{III- Light microscopy (Fig. 7)}

Toludine blue stain: Adult control liver show its parenchyma consists of polyhedral hepatocytes with vesicular nuclei and cytoplasmic basophilic granules. Blood sinusoids, which are seen in between liver cells, lined with flat endothelial cells and kupffer cells (Fig. 7A). Apparent changes observed as compared to the control group in the form of distortion of the normal hepatic architecture. Some hepatocytes had vacuolated cytoplasm with few granules. The vacuoles may be large, varying in shape and in size, occupying most of cytoplasm and compress the nucleus. Some nuclei had irregular nuclear membrane and large margination of heterochromatin with no nucleolus. Dense apoptotic nuclei and dilatation in perinuclear membrane space were sometimes observed (Fig. 7B). Some hepatocytes showed Ground glass hepatocyte (GGH) with a flat hazy and uniformly dull appearing cytoplasm. The boundaries between the cells were ill defined. Blood sinusoids were dilated with mononuclear cellular infiltration and contained numerous large kupffer cells (Fig. 7D). In groups IIb and IIIb showed most of the hepatocytes contained vesicular nucleus with prominent nucleolus. The cytoplasm contained highly basophilic patches and rarely vacuolated cytoplasm compared to that of group IIIa. Some hepatocytes enlarged in size and contained vacuolated cytoplasm with varying shape and size showed nuclei with margination of heterochromatin with no nucleolus, others were dense small apoptotic nuclei with irregular nuclear envelope (Fig. 7C and E).

\section{IV-Electron microscopy (Fig. 8)}

Adult control liver revealed hepatocytes with euchromatic nucleus, prominent nucleolus, abundant mitochondria, and rER appeared as parallel tubules around nucleus and between mitochondria (Fig. 8A).

In group IIa, hepatocytes showed marked degenerative changes as cytoplasm appeared rarified, contained few organelles and numerous vacuoles of variable shapes and sizes and contained lysosomes with no rER (Fig. 8B).

In group IIIa, most of the mitochondria decreased in size and contained dense material. RER appeared in the form of parallel tubules in close association with mitochondria. Smooth endoplasmic reticulum appeared as dilated vesicles (Fig. 8D). In groups IIb and IIIb, the hepatic cytoplasm was less vacuolated compared to the previous treated group. The nucleus appeared rounded with euochromatin and prominent peripheral nucleolus. Most mitochondria were slightly enlarged with dense material inside. rER tubules were in close association with it and around the nucleus. Glycogen was observed as small dark granules in close relation to smooth endoplasmic reticulum (Fig. 8C and E).

\section{V-Immunohistochemistry}

\section{A- P53 marker: (Fig. 9)}

No P53 positive cells were noticed in the control group (Fig. 9A). P53 positive-hepatocytes observed in treated groups; group IIa and group IIIa (Fig. 9B andD). The number of positive cells decreased in group IIb and group IIIb compared to group IIa and group IIIa (Fig. 9 C and E).

\section{b- PCNA marker: (Fig. 10)}

Few weakly stained nuclei are seen in the control group (Fig. 10A). Treated group showed an increase in the positively stained nuclei of most of the hepatocyte (Fig. $10 \mathrm{~B})$. In higher dose, liver sections showed stained nuclei of hepatocytes increased dramatically both in the intensity of the immunostaining as well as in the number of PCNA positive hepatocytes (Fig. 10D). The number of PCNA positive stained nuclei decreased in groups IIb and IIIb compared to those of groups IIa and IIIa (Fig. $10 \mathrm{C}$ and E). 


\section{VI- Morphometric studies}

The morphometric studies and statistical analysis performed on the liver sections included the study of the mean of positive cells for p53 stain and of the mean of positive cells for PCNA stain. The study revealed the following results:

A-The mean of positive cells for $\mathrm{p} 53$ stain:

There was very highly significant difference $(* * * *)$ in groups IIa, IIIa and IIIb versus the control group as regard to the mean of positive cells for p53 stain ( $p$ value $<0.0001$ ). No significant $(\mathrm{NS})$ difference between group IIb compared to the control group ( $p$ value $>0.05$ ). The summary of the means values of these groups are shown in (Table 2) and (Figure 11).

B-The mean of positive cell in PCNA stain

There was very highly significant difference $(* * * *)$ in all different treated groups versus the control group as regard to the mean of positive cells for PCNA stain ( $p$ value $<0.0001$ ). The summary of the means values of these results are shown in (Table 3) and (Figure 12).

Table 1: ALPs, ALT and AST levels in different groups.

\begin{tabular}{lccc}
\hline & $\begin{array}{c}\text { ALPs level } \\
(\text { mean } \pm \text { SD })\end{array}$ & $\begin{array}{c}\text { ALT level } \\
(\text { mean } \pm \text { SD })\end{array}$ & $\begin{array}{c}\text { AST level } \\
(\text { mean } \pm \text { SD })\end{array}$ \\
\hline Control & $102.33(2.78)$ & $46.00(1.73)$ & $192(6.24)$ \\
G r o u p & $256.67(23.40)$ & $53.67(1.32)$ & $174.67(5.07)$ \\
IIa & & & \\
G r o u p & $178.67(23.11)$ & $46.67(2.64)$ & $172.67(7.37)$ \\
IIb & & & $177.67(22.15)$ \\
G r o u p & $419.33(112.70)$ & $66.33(5.07)$ & \\
IIIa & & & \\
G r o u p & $204.33(34.04)$ & $53.67(2.65)$ & $183.00(16.04$ \\
IIIb & & & \\
P value & $<0.0001(* * *)$ & $<0.0001(* * * *)$ & $0.03(\mathrm{NS})$ \\
\hline
\end{tabular}

Table 2: Means of the positive cells for p53 in different groups.

\begin{tabular}{lcccc}
\hline & mean & SD & SE & P value \\
\hline Control & 2.4 & 2.366 & 0.748 & \\
Group IIa & 31.5 & 14.144 & 4.473 &, $000(* * * *)$ \\
Group IIb & 9,2 & 4,341 & 1,373 &, $157(\mathrm{NS})$ \\
Group IIIa & 53,8 & 12.994 & 4.109 &, $000(* * * *)$ \\
Group IIIb & 28,5 & 9,629 & 3.045 &, $000(* * * *)$ \\
\hline
\end{tabular}

Table 3: Means of the positive cells for PCNA in different groups.

\begin{tabular}{lcccc}
\hline & Mean & SD & SE & P value \\
\hline Control & 6,5 & 5,4 & 1,7 & \\
GroupIIa & 63,3 & 15,8 & 5 &, $000(* * * *)$ \\
GroupIIb & 28,2 & 11,5 & 3,6 &, $000(* * * *)$ \\
GroupIIIa & 77,3 & 20,8 & 5,6 &, $000(* * * *)$ \\
GroupIIIb & 49,5 & 13 & 4,1 &, $000(* * * *)$ \\
\hline
\end{tabular}

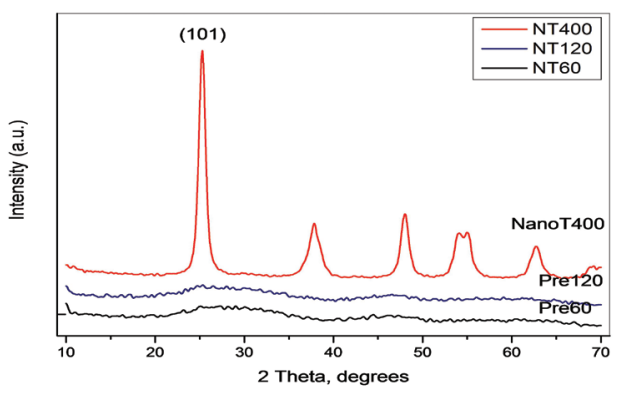

Fig. 1: XRD diffraction pattern.

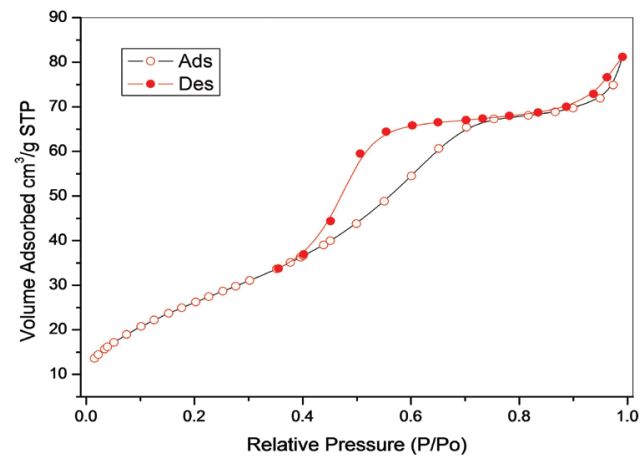

Fig. 2: N2 adsorption isotherm of NanoT400.

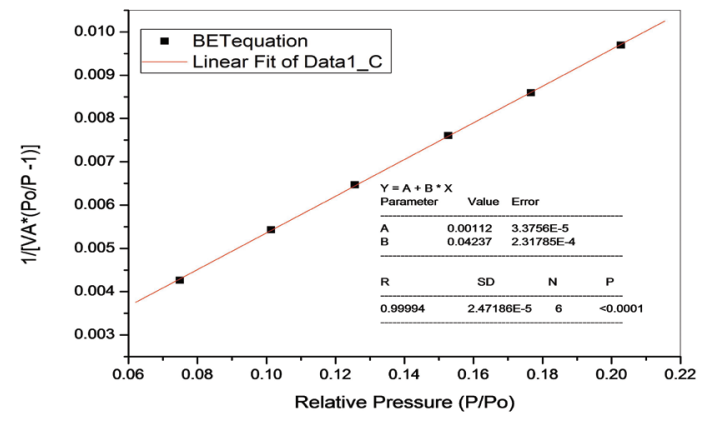

Fig. 3: BET plot for NanoT400. 


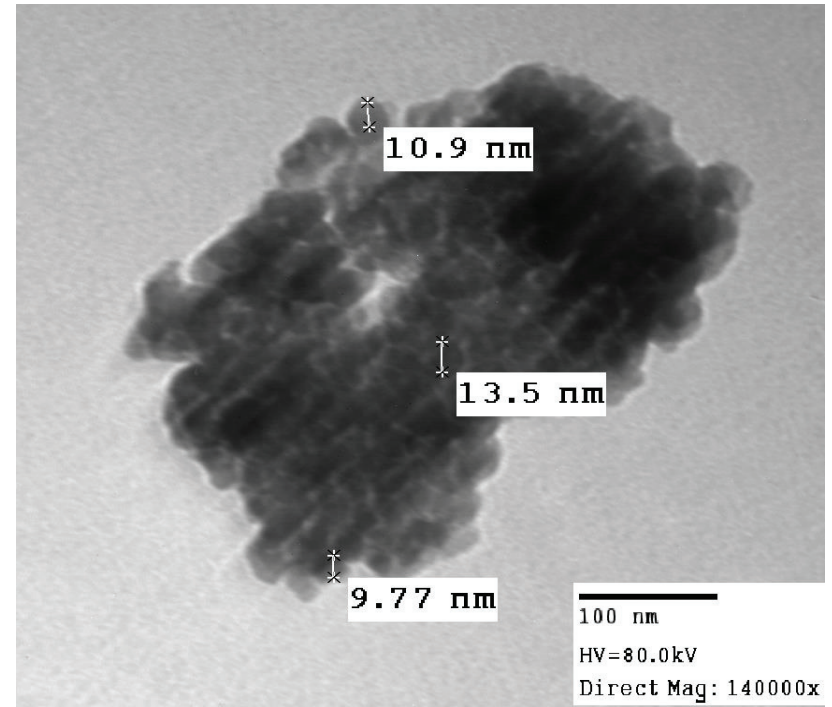

Fig. 4: TEM NanoT400 $10 \mathrm{~nm}$. (X140000)

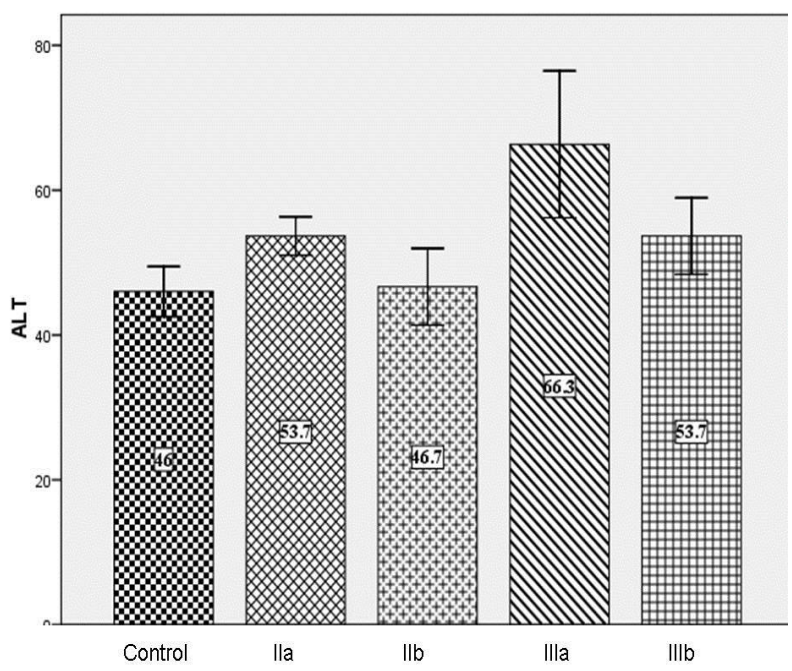

Fig. 5: ALT level in different groups.

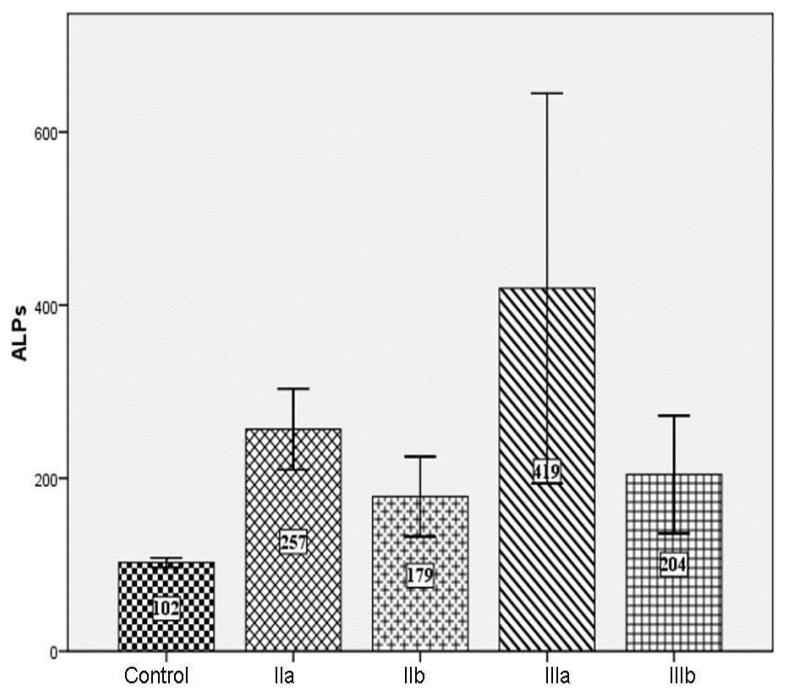

Fig. 6: ALPs level in different groups.

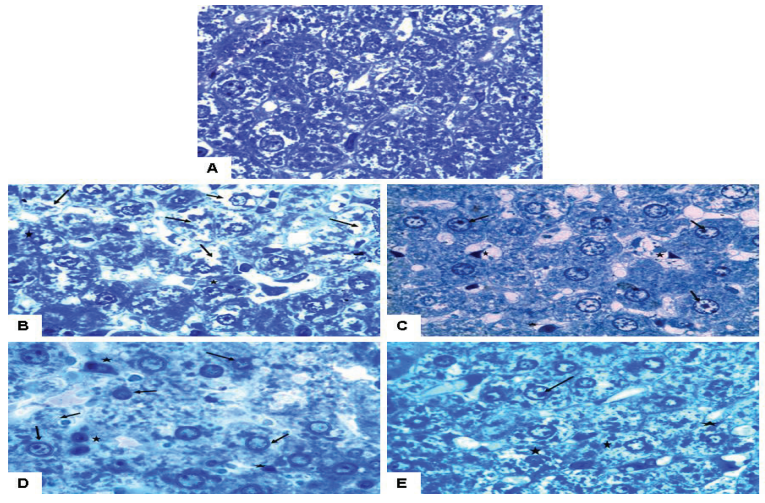

Fig. 7: A- Control showing polyhedral hepatocytes with vesicular nuclei, cytoplasmic basophilic granules and blood sinusoids lined with flat endothelial cells and kupffer cells. B(Group IIa) showing vacuolated hepatocytes (arrows) compress the nucleus with irregular nuclear membrane and dense apoptotic nuclei (stars).C- (Group IIb) showing hepatocytes with basophilic granules and vesicular nucleus with prominent nucleolus similar to control group (arrows), kupffer cells in dilated blood sinusoids (stars). D- (Group IIIa) showing nuclear margination, dense nucleus, perinuclear dilatation (arrows) and Ground glass hepatocyte (GGH) with a flat hazy and uniformly dull appearing cytoplasm, kupffer cells in dilated blood sinusoids (stars). E- (Group IIIb) showing some normal hepatocytes appeared with vesicular nuclei and prominent nucleoli (arrow), other hepatocytes contained small apoptotic nuclei with irregular nuclear envelope (stars). Note there is no dilatation of the blood sinusoids. (Toludine blue stain X1000)

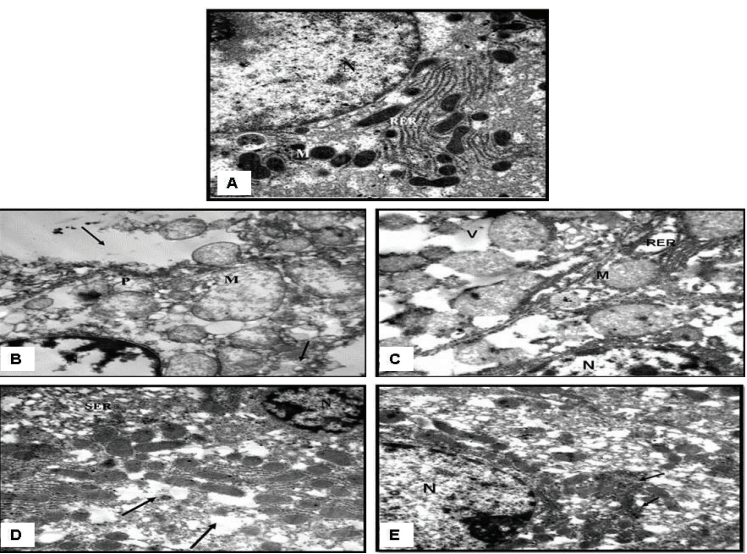

Fig. 8: A- Control showing part of nucleus $(\mathrm{N})$, abundant mitochondria (M) and rough endoplasmic reticulum (RER) appeared as parallel tubules between mitochondria and around the nucleus. B- (Group II a) showing highly vacuolated cytoplasm (arrows) with rarified appearance and contain peroxisomes (P) with no RER, swollen mitochondria with destructed cristae (M) and small nucleus $(\mathrm{N})$ with clumped chromatin. C-(Group IIb) showing moderate vacuoles $(\mathrm{V})$ variables in size and shape, a part of nucleus $(\mathrm{N})$, mitochondria $(\mathrm{M})$ slight enlarged with dense material inside it and normal RER. D-(Group III a) showed vacuoles (arrows) of variable shapes and diameters, small apoptotic nucleus $(\mathrm{N})$ and mild dilated smooth endoplasmic reticulum (SER). E-(Group IIIb) showing part of the euochromatic nucleus $(\mathrm{N})$ with peripheral prominent nucleolus and small dark glycogen granules (arrows). (X10000) 


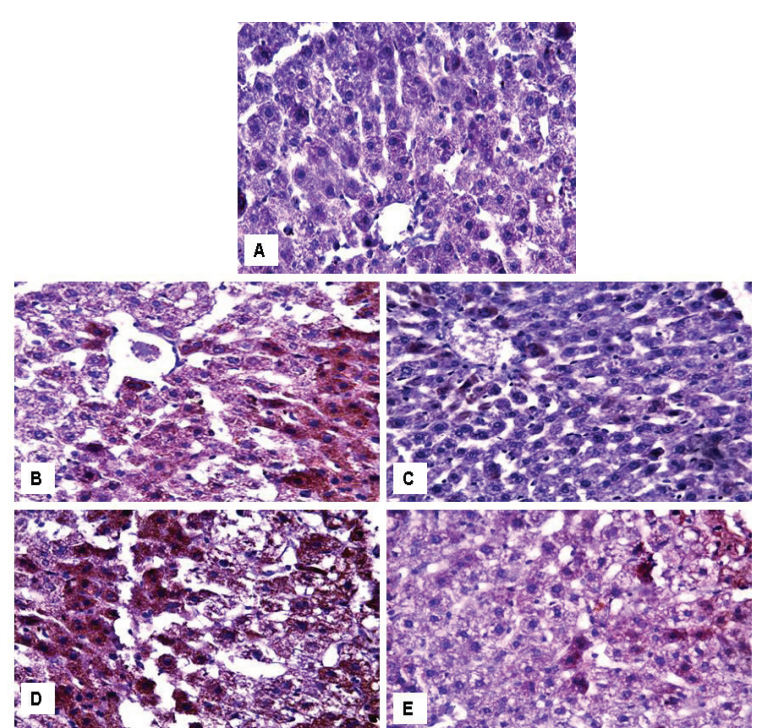

Fig. 9: A- (Group I) showing no positive cells for p53 stain. B- (Group IIa) showing positive stained cytoplasm of the hepatocytes especially those in the peripheral part of the lobules. C- (Group IIb) showing few weakly stained cells compared to group IIa. D- (Group IIIa) showing an apparent increase in the intensity and in the number of positive stained cytoplasm of the hepatocytes. E- (Group IIIb) showing decrease in the intensity and in the number of positive stained cells compared to group IIIa. (P53 stain X400)

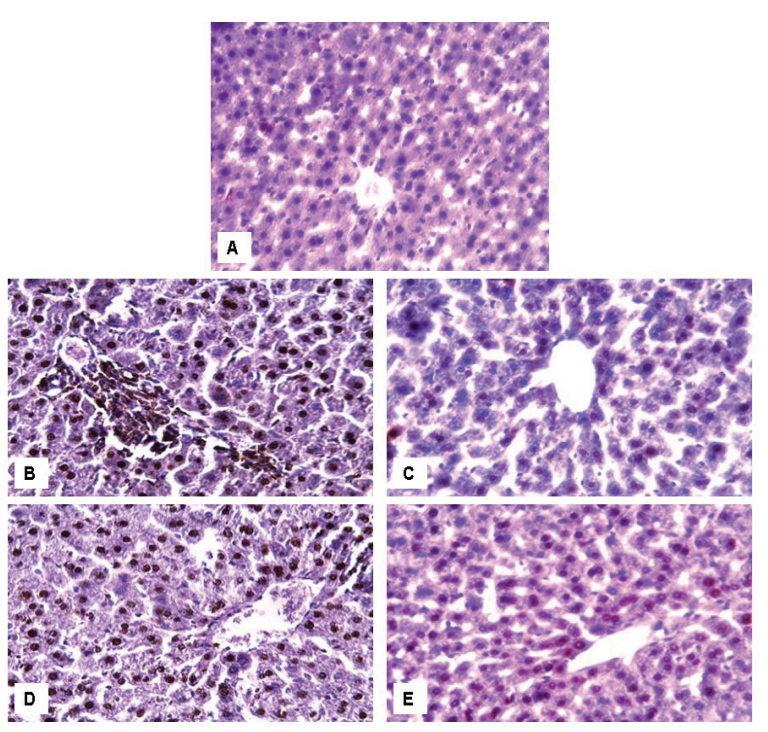

Fig. 10: A- (Group I) showing few weakly stained nuclei in the hepatocytes for PCNA stain. B- (Group IIa) showing an increase in the positively stained nuclei of most of the hepatocytes. C(Group IIb) showing a decreased in the number of positive cells compared to group IIa. D- (Group IIIa) showing an increase in the intensity of the immunostaining as well as in the number of PCNA positive hepatocytes. E- (Group IIIb) showing a decreased in the number of positive stained cells compared to those in group IIIa. (PCNA stain X400

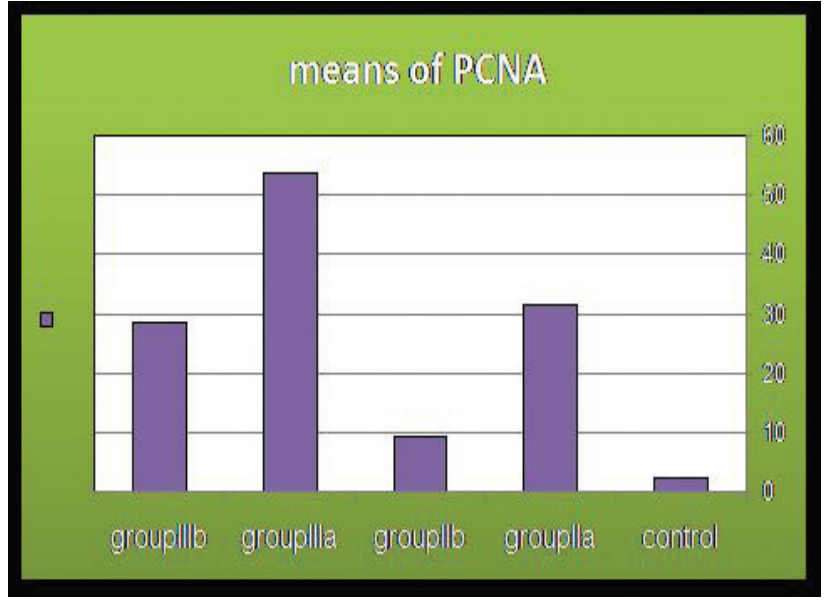

Fig. 11: Means of the positive cells for p53 in different groups.

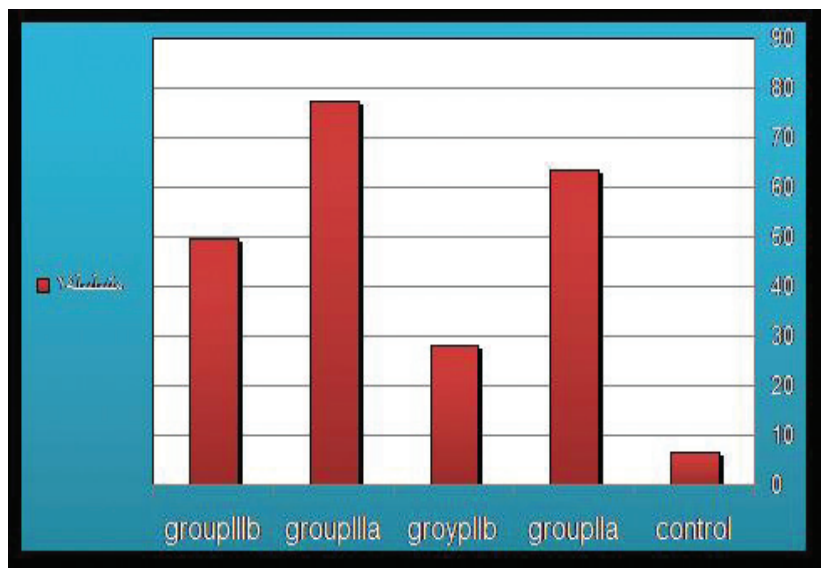

Fig. 12: Means of the positive cells for PCNA in different groups.

\section{DISCUSSION}

In our study, intraperitoneal injection of different doses of $\mathrm{TiO} 2$ NPs induced biochemical changes in the rats' livers in the form of increased ALT and ALPs levels indicating damage of liver function. Alike, Liu et al. ${ }^{[12]}$ observed marked disturbance of liver function caused by intraperitoneal injection of higher doses $(50,100$, and $150 \mathrm{mg} / \mathrm{kg} \mathrm{BW})$ of TiO2 NPs $(5 \mathrm{~nm})$ for 14 days. Also, Alarifi et al. ${ }^{[13]}$ reported a significant increase in GOT and ALPs levels with manifestations of apoptosis in liver cells in the form of small condensed nucleus and chromatinolysis with coarse clumps of heterochromatin with irregular nuclear membrane. These results agreed with Ma et al. ${ }^{[14]}$ who reported that TiO2 NPs are similar to hepatovirus, can enter liver cells or nuclei and bind to DNA and thus might cause the changes of genetic information transfer and the inflammatory cascade which induce hepatocyte apoptosis. 
While Yaling et $a l .{ }^{[15]}$ observed apoptotic cell with chromatin condensation and the apoptotic body suggested that TiO2 NPs induce hepatocyte apoptosis of mice.

The ultrastructure results revealed degenerative changes in the form of accumulation of rarified cytoplasm with destructed organelles and numerous vacuoles in the cytoplasm of hepatocyte and dilated smooth endoplasmic reticulum. Paumgartner and Beuers ${ }^{[16]}$ explained that free radicals is highly unstable and reacts with membrane components and form covalent bonds. These radicals react with molecular oxygen and initiate preoxidative decomposition of phospholipids in the endoplasmic reticulum. Furthermore, Caro and Cederbaum ${ }^{[17]}$ proved that cytochrome P450 (CYP1A) which presents in SER showed high level due to TiO2 NPs induction and cause hepatocyte toxicity.

The most prominent alternation in hepatocyte was mitochondrial swelling with destructed cristae and dense material inside it. Mitochondrial affection may play an important role in the process of cellular apoptosis. When TiO2 NPs invaded mitochondria, its antioxidant defense ability could be altered. Danz et al. ${ }^{[18]}$ previously reported that inner mitochondria membrane plays a role in toxicity as it is a major source of ROS which cause damage to lipids, proteins and DNA and lead to loss of the cellular function especially in necrotic and apoptotic cells. They added another explanation that ROS play a role in promoting cytochrome $\mathrm{c}$ release from mitochondria into the cytoplasm which cause activation of the caspase cascade lead to apoptosis. These results were supported by Beere and his colleagues ${ }^{[19]}$ who said that opening of the mitochondrial permeability transition pore and the disruption of mitochondrial transmembrane potential are also central steps in the apoptotic cell death signaling pathway. Long et al. ${ }^{[20]}$ stated that overproduction of ROS would break down the balance of the oxidative/ antioxidative system in the liver, resulting in the lipid peroxidation and the hepatocyte apoptosis. $\mathrm{TiO} 2$ reduced the antioxidative enzymes like SOD, CAT, and GSH-Px as well as non-enzymatic antioxidants like ascorbate and GSH. The dense material observed in our study may be explained by $\mathrm{Ma}$ and his associates ${ }^{[14]}$ who stated that $\mathrm{TiO} 2$ NPs are not freely distributed in the cytoplasm after being internalized by cells but is preferentially located in the mitochondria.

The increased peroxisomes in our research were previously explained by $\mathrm{Suga}^{[21]}$ and Titorenko ${ }^{[22]}$ to be directly associated with increased hepatocyte proliferation, besides playing a role in lipid metabolism and hydrogen peroxide detoxification.

The increased cytoplasmic p53 expression was an apoptotic marker of hepatocytes in all treated groups and this increase was dose dependent increased in higher doses. Forrester et al. ${ }^{[23]}$ found that $\mathrm{TiO} 2$ NPs cause oxidative stress and chronic inflammation are associated with high concentrations of NO products which can cause DNA damage, either directly or through secondary molecules, by nitroso-active deamination, DNA strand breakage and DNA modifications. NO-induced DNA damage can lead to p53 accumulation in cytoplasm and p53 mediated apoptosis. Thus, higher basal levels of p53 may function to protect hepatocytes from DNA damage. Absence of p53 expression in the nuclei may be explained by Wang and Lui. ${ }^{[24]}$, who reported that p53 protein accumulate in the cytoplasm with absolute nuclear sparing. Thus, NO protein may be directly involved in the sequestration of $\mathrm{p} 53$ protein in the cystol and block of p53 entry into nucleus. Noteworthy, Moll et al. ${ }^{[25]}$ and Stommel et al. ${ }^{[26]}$ had another explanation that cytoplasmic sequestered p53 has been considered as a defect in p53 nuclear retention resulting from either inhibition of its entry into the nucleus or from its hyperactive export in some toxic cells ${ }^{[27,28]}$.

In addition PCNA is closely associated with cell cycle and its expression increases at the end of G1 phase, reaches its maximum in S-phase, declines during G2 phase and is absent during the mitotic phase and in quiescent cells ${ }^{[29]}$. The morphometric studies in the present work revealed that control liver showed few PCNA positive cells. In contrast, liver sections treated by $\mathrm{TiO} 2$ NPs showed bile duct proliferation and significant increase in the number of PCNA positive cells. Liver cells were found to be capable of proliferation in normal conditions. This proliferative activity increased in case of liver injury ${ }^{[30]}$. The increased expression of PCNA in hepatocytes in treated groups indicates a sort of compensation by proliferation of hepatocytes and increase extracellular matrix synthesis ${ }^{[31]}$ or by proliferation of liver's resident stem cells ${ }^{[32]}$. This is in line with Gerlyng et al. ${ }^{[33]}$ and Alarifi et al. ${ }^{[13]}$ who found that nuclear polymorphism seen in hepatic dysplasia and binucleation represents a consequence of cell injury as a sort of chromosomal hyperplasia in regenerating cells.

Hepatoprotective effects of Milk thistle supported by Post-White et al. ${ }^{[6]}$ who reported that it impaired oxidative stress through decreased production of free radical derivatives, by the decreased CYP enzyme activity, MDA level and glutathione level which has antioxidant properties that protects against liver damage. Nirav et al. [34] found that increase in $\mathrm{p} 53$ protein is consistent with Dox-induced DNA fragmentation and silymarin decrease p53 protein toward normal values with protection of genomic DNA. Our results also coincide with the previous results that Milk thistle can reduce or prevent liver damage by TiO2 NPs as well as due to other hepatotoxic agents like; antineoplastic drug doxorubicin (Dox), ethanol ${ }^{[35]}$ and $\mathrm{CCl}^{[36]}$. Zhou et al. ${ }^{[37]}$ reported that silibinin, a plant flavanoid 
from milk thistle, reduced isoproterenol-induced cardiac myocyte apoptosis through decrease NO production, Bax, p53 and caspases.

\section{CONCLUSION}

Our results add to our understanding of TiO2 NPs induced- liver injury. Milk thistle is a safe hepatoprotective herbal dietary supplement is recommended to prevent $\mathrm{TiO} 2$ NPs induced-hepatocellular damage and liver fibrosis.

\section{CONFLICT OF INTEREST}

There are no conflicts of interest.

\section{REFERENCES}

1. Peralta-Videa J R, Zhao L, Lopez-Moreno M L, de la Rosa G, Hong J and Gardea-Torresdey J L. (2011): Nanomaterials and the environment. J Hazard Mater; 186: 1-15.

2. Warheit D B, Hoke R A, Finlay C, Donner E M, Reed K L and Sayes C M. (2007): Development of a base of toxicity tests using ultrafine $\mathrm{TiO} 2$ particles as a component of nanoparticle risk management. Toxicol. Lett.; 171: 99-110.

3. Li Y F and Chen C. (2011): Fate and toxicity of metallic and metal-containing nanoparticles for biomedical applications. Small; 7: 2965-2980.

4. Wang J X, Zhou G Q, Chen C Y, Yu H W, Wang T C and Ma Y M. (2007): Acute toxicity and biodistribution of different sized titanium dioxide particles in mice after oral administration. Toxicol Lett; 168: 176-185.

5. Li J J, Muralikrishnan $\mathrm{S}, \mathrm{Ng} \mathrm{C} \mathrm{T}$, Yung $\mathrm{L} \mathrm{Y}$ and Bay B H. (2012): Nanoparticle-induced pulmonary toxicity. Exp Biol Med (Maywood); 235: 1025-1033.

6. Post-White J, Ladas E J and Kelly K M. (2007): Advances in the use of milk thistle (Silybum marianum). Integr Cancer Ther; 6: 104-109.

7. Vaknin Y, Hadas R, Schafferman D, Murkhovsky L and Bashan N. (2007): The potential of milk thistle (Silybum marianum L.), an Israeli native, as a source of edible sprouts rich in antioxidants. Int J Food Sci Nutr; 20: 1-8.

8. Moon Y J, Cheon H J, Lee W C, Kim H Y, Oh S Tand Shin E J. (2008): Protective effect of
ACTIValoe ${ }^{\circledR N}$-931 complex, a mixture of nanoparticles trigger p53-mediated damage response in peripheral blood lymphocytes. Environ Mol Mutagen; 49: 399-405.

9. Khalil K M, Baird T, Zaki M I, El-Samahy A A and Awad A M. (1998): Synthesis and characterization of catalytic titanias via hydrolysis of titanium (IV) isopropoxide. Colloids and Surfaces A; 132: 31-44.

10. Choi H, Stathatos E and Dionysiou D D. (2006): Sol-gel preparation of mesoporous photocatalytic $\mathrm{TiO} 2$ films and $\mathrm{TiO} 2 / \mathrm{A} 12 \mathrm{O} 3$ composite membranes for environmental applications. Appl. Catal. B: Environ; 63: 560-567.

11. JCPDS, International Centre for Diffraction Data, PCPDFWIN, JCPDSICDD. (1995).

12. Liu H T, Ma L L, Zhao J F, Liu J, Yan J Y, Ruan J and Hong F S. (2009): Biochemical toxicity of mice caused by nano-anatase $\mathrm{TiO} 2$ particles. Biol. Trace Elem. Res.; 129 (1): 170-180.

13. Alarifi S, Daoud A, Amin A A, Bahy A A, Mukhtar A and Abdulaziz A A. (2013): Histologic and apoptotic changes induced by titanium dioxide nanoparticles in the livers of rats. International Journal of Nanomedicine. Dove press journal; 8: 3937-3943.

14. Ma L L, Zhao J F, Wang J, Duan Y M, Liu J, Li N, Liu H T, Yan J Y, Ruan J and Hong F S. (2009): The acute liver injury in mice caused by nanoanatase TiO2. Nanoscale Res. Lett; 4: 1275-1278.

15. Yaling C, Xiaolan G, Yanmei D, Na L, Renping $\mathrm{H}$, Huiting L, Mengmeng H, Min Z, Ling W, Han W and Fashui H. (2010): Hepatocyte apoptosis and its molecular mechanisms in mice caused by titanium dioxide nanoparticles. Journal of Hazardous Materials; 183: 874-880.

16. Paumgartner G and Beuers U. (2004): Mechanisms of action and therapeutic efficiency of ursodeoxycholic acid in cholestatic liver disease. Clinics in liver disease. Elsevier Saunders; 8: 67-81.

17. Caro A A and Cederbaum A I. (2004): Oxidative stress, toxicology of CYP2E1 and cell. J. Cell Biol; 164: 641-645.

18. Danz E D, Skramsted J and Henry N. (2009): Resveratrol prevents Doxorubicin cardiotoxicity through mitochondrial stabilization and the Sirt1 
pathway. Free Radic. Biol. Med; 46: 1589-1597.

19. Beere H M, Wolf B B, Cain K, Mosser D D, Mahboubi A, Kuwana T, Tailor P, Morimoto R I, Cohen G M and Green D R. (2010): Oxidative stress in the brain of mice caused by translocated nanoparticulate $\mathrm{TiO} 2$ delivered to the abdominal cavity. Biomaterials; 31 (5): 99-105.

20. Long $\mathrm{T}$ C, Saleh N, Tilton R D, Lowry G and Veronesi B. (2006): Titanium dioxide (P25) produces reactive oxygen species in immortalized brain microglia (BV2): implications for nanoparticle neurotoxicity. Environ. Sci. Technol; 4346-4352.

21. Suga T. (2004): Hepatocarcinogenesis by peroxisome proliferators. J. Toxicol. Sci; 29: 1-12.

22. Titorenko V I and Rachubinski R A. (2004): The peroxisome. Toxicol. Sci; 91 (1): 227-236.

23. Forrester K, Ambs S and Lupold S E. (1996): Nitric oxide-induced p53 accumulation and regulation of inducible nitric oxide synthase expression by wild-type p53. Proc Natl Acad Sci U S A; 93: 2442-2447.

24. Wang C and Liu Z. (2006): Arabidopsis ribonucleotide reductases are critical for cell cycle progression, DNA damage repair, and plant development. Plant Cell; 18: 350-365.

25. Moll U M, Ostermeyer A G, Haladay R, Winkfield B, Frazier M and Zambetti G. (1996): Cytoplasmic sequestration of wild-type p53 protein impairs the G1 checkpoint after DNA damage. Mol Cell Biol; 16: 1126-1137.

26. Stommel J M, Marchenko N D, Jimenez G S, Moll U M, Hope T J, and Whal G M. (1999): A leucinerich nuclear export signal in the p53 tetrameization domain: regulation of subcellular localization and p53activity by NES masking. EMBO J; 18: 1660-72.

27. Denissenko M F, Koudriakova T B, Smith L, O'Connor T R, Riggs A D and Pfeifer G P. (1998): The p53 codon249 mutational hotspot in hepatocellular carcinoma is not related to selective formation or persistence of aflatoxin B1 adducts. Oncogene; 17: 3007-3014.

28. Lim I K. (2002): Spectrum of molecular changes during hepatocarcinogenesis induced by DEN and other chemicals in Fisher 344 male rats. Mech Ageing Dev; 123: 1665-1680.

29. Dworakowska D, Gozdz S and Jassem E. (2002): Prognostic relevance of proliferating cell nuclear antigen and p53 expression in effects of Paullinia cupana Mart var. sorbilis, the guarana, on mouse hepatocarcinogenesis. Cancer Lett; 233: 158-164.

30. Fukumasu H, da Silva T C and Avanzo J L. (2006): Chemopreventive effects of Paullinia cupana Mart var. sorbilis, the guarana, on mouse hepatocarcinogenesis. Cancer Lett; 233: 158-164.

31. Yoshiji H, Kuriyama S, Yoshii J, Ikenaka Y, Noguchi R and Nakatani T. (2002): Tissue inhibitor of metalloproteinases-1 attenuates spontaneous liver fibrosis resolution in the transgenic mouse. Hepatology; 36: 850-860.

32. Allameh A and Kazemnejad S. (2012): Safety evaluation of stem cells used for clinical cell therapy in chronic liver diseases; with emphasis on biochemical markers. Clin Biochem.; 45: $385-396$

33. Gerlyng P, Åbyholm A and Grotmol T. (2008): Binucleation and polyploidization patterns in developmental and regenerative rat liver growth. Cell Prolif; 26: 557-565.

34. Nirav P, Cecil J, George B. C and Sidhartha D. R. (2010): Silymarin modulates doxorubicin- induced oxidative stress, Bcl-xL and p53 expression while preventing apoptotic and necrotic cell death in the liver. Toxicology and Applied Pharmacology; 245: $143-152$

35. Baek M W, Seok S H, Lee H Y, Kim D J, Lee B H, Ahn Y T, Lim K S, Huh C S and Park J H. (2005): Protective Effect of Y-mix in an Ethanol-induced Toxicity Model. Lab Anim Res; 21: 413-417.

36. Sung B, Kunnumakkara A B and Sethi G. (2009): Curcumin circumvents chemoresistance in vitro and potentiates the effect of thalidomide and bortezomib against human multiple myeloma in nude mice model. Mol. Cancer Ther; 8: 959-970.

37. Zhou B, Li-jun W, Shin-ichi T and Satoshi O. (2006): Silibinin reduced isoproterenol-induced cardiac myocyte apoptosis through decrease NO production, Bax, p53 and caspases. Biological\& Pharmaceutical Bulletin; 29 (9): 1900-1905. 
الملخص العربى

\section{تأثير ات الكيمياء نسيجية والكيمياء حيوية لجزيئات ثاني أكسيد التيتانيوم المتناهية في الصغز علي

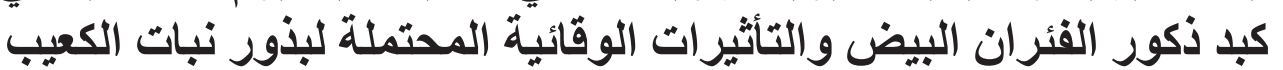

\section{إيمان السيد أبو ضيف1 ، حكمت عثمان عبد العزيز1 ، إيمان خليفة نورالدين1 ، كمال خليل2 ، إيمان

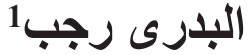

\section{1قسم الههتولوجى، كلية الطب ، 2قسم الكيمياء ، كلية العلوم ، جامعة سوهاج ، سوهاج ، مصر}

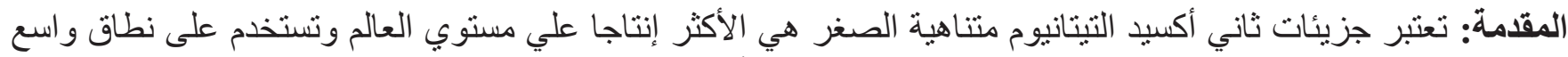

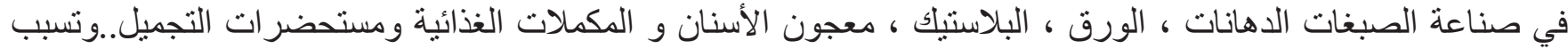

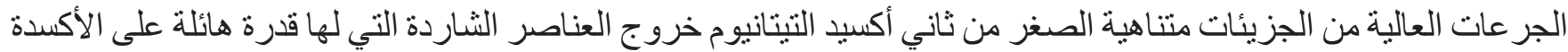

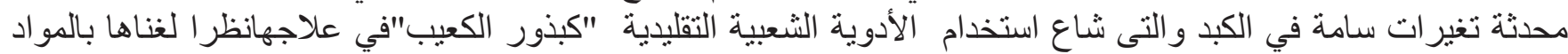
المضادة للاككسة.

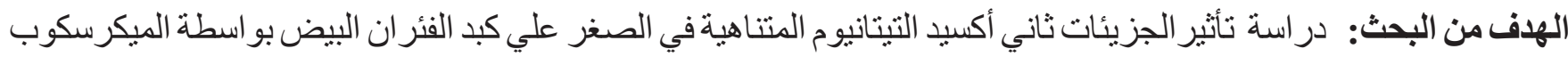

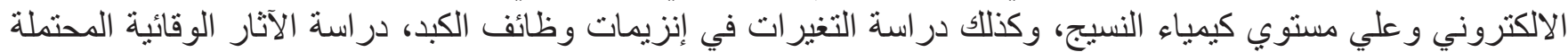

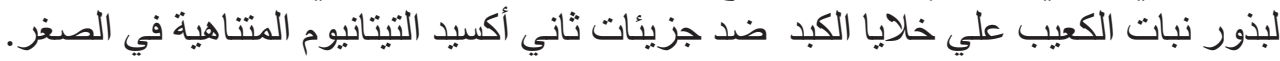

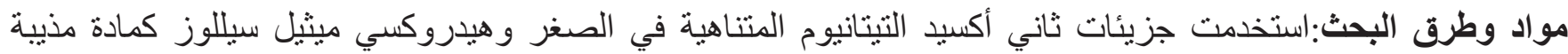

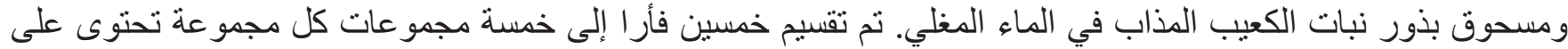

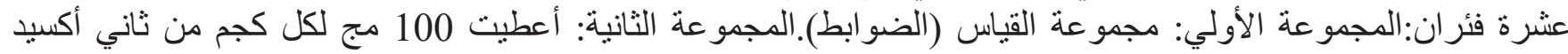

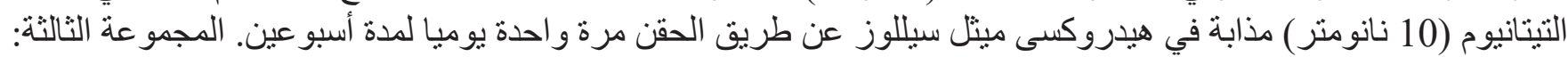

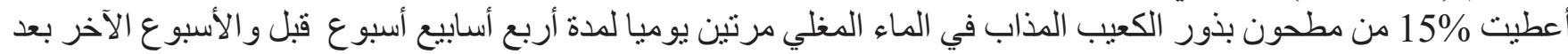
إعطاءه 100مجم لكل كجم من ثاني أكسيد التيتانيو لمده أسبو عين.

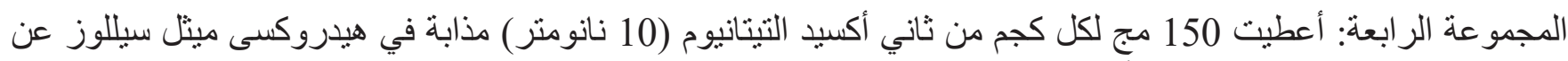
طريق الحقن مرة واحدة يوميا لمدة أسبو عين. المجمو عة الخامسة : أعطيت 15\% من مطحون بذورة الأبور الكعيب المذاب في الماء المغلي مرتين يوميا لمدة أربع أسابيع أسبوع قبل

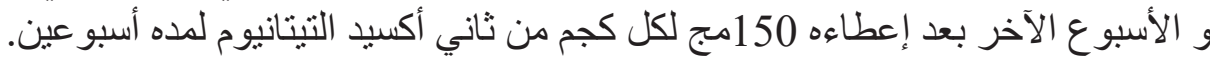

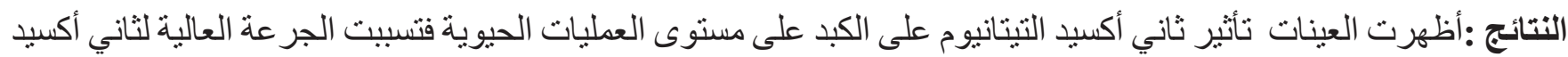

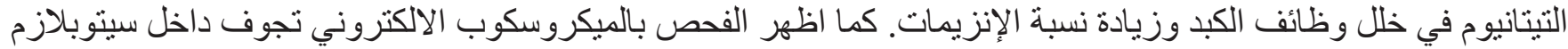

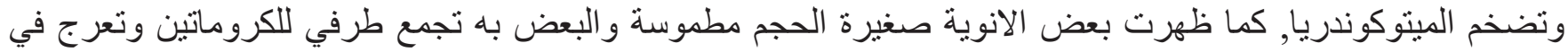

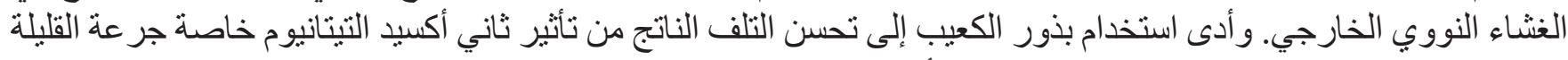
عن طريق تجديد الخلايا الكبدية وزيادة مضادات للأكسدة.

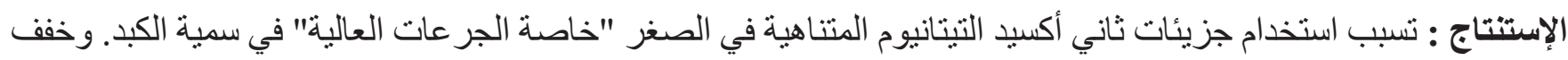

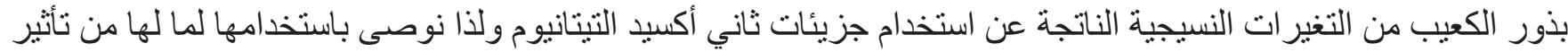
وقائي و علاجي علي الكبد ومنع تقدم التليف الكبدي لني 